\title{
"There is a possibility that..."-Shell Nouns in Academic Writing by Chinese and Swedish
}

\author{
Yishan Gao, Yi Zhang* \\ School of Foreign Languages, Northwestern Polytechnical University, Xi'an, Shaanxi Province, China
}

Copyright $\mathrm{O} 2018$ by authors, all rights reserved. Authors agree that this article remains permanently open access under the terms of the Creative Commons Attribution License 4.0 International License

\begin{abstract}
This paper analyzes the use of a special type of abstract nouns, shell nouns, in two corpora consisted of 60 research articles published by scholars from China and Sweden. The frequency, classes, lexico-grammatical patterns and premodifiers of shell nouns are investigated in this study. The results indicate that though in general Chinese use significantly less shell nouns than their Swedish counterparts, especially in the cognition class of shell nouns, there is no significant difference between the two groups of authors in other classes, lexico-grammatical patterns or premodifiers of shell nouns. A possible explanation for the results is offered from the perspective of genre and discourse community. Pedagogical suggestions based on these findings are also illustrated for the teaching of shell nouns.
\end{abstract}

Keywords Shell Noun, Academic Writing, Corpus Linguistics, Chinese and Swedish

\section{Introduction}

As a special type of abstract nouns, shell nouns such as fact, problem, type, method and issue work as shells because "when they are used in this function, they can enclose or anticipate the meaning of the preceding or succeeding discourse" [1]. There are many ways to name a shell noun, like general noun [2], anaphoric noun [3], and carrier noun [4]. However, no matter what the names are, these nouns have one common feature: they have both a fixed meaning and a changeable meaning which needs to be referred from the context they appear in [4]. Previous studies on shell nouns focused on various aspects, such as functions [5], lexico-grammatical patterns [6], classifications [7], premodifiers [8] and errors in using shell nouns [9]. The data studied include master theses [6], journal articles [1], argumentative essays [10] and even dictionaries [11]. Contrastive studies of shell nouns usually aim to compare people with different language proficiencies, like expert and novice writers [1], research papers in different disciplines, such as natural and social sciences [12], or writing productions by native and non-native speakers of English [13]. However, few papers have investigated the use of shell nouns by two groups of non-native speakers of English. Therefore, whether shell nouns are used differently in the English productions by scholars from two non-English speaking countries remains unknown yet.

Language learners gradually realize that in order to master a foreign language, they need to understand the characteristics of that language and the most efficient method to do so is to compare that language with their mother tongue [14]. When language users are faced with complicated linguistic phenomena of a foreign language, resorting to their mother tongue may improve their language proficiency. It is possible, however, that their first language interferes with the acquisition of a second language. Interlanguage is defined as "the separateness of a second language learner's system, a system that has a structural intermediate status between the native and target languages [15]". With different first languages, scholars from non-English speaking countries are possible to acquire interlanguages with various features. Starting from this point, this study employs a corpus-based approach to compare the shell nouns used by scholars from China and Sweden. These two countries have been selected to represent, to a certain degree, English users from Asia and Europe, or in other words, users from the East and the West. The questions which are intended to be answered in the present paper are as follows:

1. What are the frequencies of shell nouns used in research articles by Chinese and Swedish scholars?

2. What classes of shell nouns do Chinese and Swedish scholars adopt?

3. What lexico-grammatical patterns of shell nouns do Chinese and Swedish scholars choose?

4. What types of premodifiers of shell nouns do Chinese and Swedish scholars use? 


\section{Conceptual Framework}

Schmid [5] points out that "it is vital for the communicative success of shell nouns that they are interpreted together with their content". Such a "co-interpretation" is triggered by lexico-grammatical patterns speakers use to link shell nouns to their contents. According to him, shell nouns are usually inserted in four patterns: shell noun + postnominal clause, shell noun + be + complementing clause, referring item $+($ premod $)+$ shell noun and referring item as subject + be + shell noun (phrase). Table 1 gives a detailed illustration of the variants of each pattern and their abbreviations. In the present paper, the first two patterns are selected for a comparison, as each of them has several variants and thus can be more beneficial and suitable for a deep analysis of the comparison of lexico-grammatical patterns. After reviewing previous researches on patterns of shell nouns $[12,16,17]$, the variant of-prepositional clause which is also frequently adopted in academic writing is added to the analysis.

Table 1. Lexico-grammatical patterns of shell nouns put forward by Schmid [5]

\begin{tabular}{|c|c|c|}
\hline Pattern & Abbreviation & Example of the general pattern \\
\hline Shell noun + postnominal clause & $\mathrm{N}-\mathrm{cl}$ & Mr. Bush said Iraq's leaders had to face the fact that the rest of \\
\hline Variants: that-clause & $\mathrm{N}$-that & the world was against them. \\
\hline to infinitive-clause & N-to & \\
\hline wh-clause & $\mathrm{N}-w h$ & \\
\hline Shell NP + be + complementing clause & $\mathrm{N}-b e-\mathrm{cl}$ & The advantage is that there is a huge audience that can hear \\
\hline Variants: $\quad$ that-clause & N-be-that & other things you may have to say. \\
\hline to infinitive-clause & N-be -to & \\
\hline wh-clause & $\mathrm{N}-b e-w h$ & \\
\hline Referring item $+($ premod $)+$ shell noun & $t h-\mathrm{N}$ & $\begin{array}{l}\text { (Mr. Ash was in the clearest possible terms labeling my clients } \\
\text { as anti-semitic.)I hope it is unnecessary to say that this } \\
\text { accusation is also completely unjustified. }\end{array}$ \\
\hline Referring item as subject $+b e+$ shell noun (phrase) & th-be-N & $\begin{array}{l}\text { (I won the freshmen's cross-country.) That was a great } \\
\text { achievement, wasn't it? }\end{array}$ \\
\hline
\end{tabular}

Adapted from [5] (p.22)

Two of Jiang's contributions [8] to the research on shell nouns are his numerous comments on previous classifications $[3,5,18,19]$ and his proposition of a method which includes not only the interactive function of shell nouns, but also their interactional function. According to Jiang (ibid), there are two weaknesses in previous classifications of shell nouns or similar types of nouns. First, previous researchers classified nouns indicating the users' attitudes or judgments into the "fact" class which only contained non-emotional words. Secondly, Jiang thought Schmid [5] and Flowerdew [19] did not effectively distinguish between "factual" nouns and "modal" nouns. In order to remedy the weaknesses of previous classifications, Jiang paid more attention to the interactional function of shell nouns while categorizing them. In his categorization, shell nouns are "functionally used either to mark entities, describe attributes of entities or to discuss the relations between entities" [8]. Table 2 presents the description of and examples for each category and sub-category.

Table 2. Classification of shell nouns proposed by Jiang [8]

\begin{tabular}{|c|c|c|}
\hline Entity & Description & Examples \\
\hline object & concretizable meta-texts & essay, report, paper \\
\hline event & events, processes, states of affairs & change, process, evidence \\
\hline discourse & verbal propositions and speech acts & argument, claim, conclusion \\
\hline cognition & cognitive beliefs and attitudes & decision, idea, belief, doubt \\
\hline Attribute & Description & Examples \\
\hline quality & traits that are admired or criticized, valued or depreciated & advantage, difficulty, value \\
\hline manner & circumstances of actions and state of affairs & means, method, way, extent \\
\hline status & epistemic, deontic and dynamic modality & possibility, trend, choice, ability \\
\hline Relation & Description & Examples \\
\hline cause-effect, etc. & cause and effect, difference, relevance & reason, result, difference \\
\hline
\end{tabular}

Adapted from [8] (p.94)

Premodifiers are another important aspect to analyze how speakers use shell nouns to convey their attitude and stance. Schmid [5] classifies the adjectives occurring in front of shell nouns into five groups: descriptive adjectives (e.g. unsuccessful/unprecedented), evaluative adjectives (e.g. terrible/tremendous), classifying adjectives (e.g. scientific/medical), restrictive adjectives (e.g. main/only), and cohesive adjectives (e.g. next/other). In the present paper, 
adjectives used before shell nouns are collected, for the purpose of finding whether Chinese and Swedish scholars employ them in a similar way or not.

\section{Corpora and Data Collection}

Two corpora of 60 journal articles written by Chinese and Swedish scholars have been compiled for the means of this study. Their general information is presented in Table 3. In order to make sure the research results will not be influenced by disciplinary variation, the research areas of the articles in the two corpora and the number of texts in each area are the same.

Table 3. General description of the two corpora

\begin{tabular}{|c|c|c|c|}
\hline Corpus & Number of papers & Number of words & Research areas \\
\hline Chinese & 30 & 135,406 & Agriculture, Biology \& Environmental Sciences; Engineering, Computing \\
\hline Swedish & 30 & 130,046 & $\begin{array}{l}\text { \& Technology; Physical, Chemical \& Earth Sciences; Science \& } \\
\text { Technology }\end{array}$ \\
\hline
\end{tabular}

The research papers in the two corpora underwent a strict selection. First, the selected papers were all indexed by Science Citation Index (SCI), a citation index covering the world's leading journals of science and technology, which allowed the quality of these papers to be on the same level. When searching research papers, many of them were joint contributions by scholars from two or more countries. Since English users have developed certain linguistic habits when acquiring their first language, new linguistic habits will be influenced by that language when people try to learn a second language [20]. For the sake of minimizing first language transfer by scholars whose first language is neither Chinese nor Swedish, the author names in Chinese Corpus were checked, and only those written by Chinese authors were included. A native Swede was invited to do this step for Swedish Corpus. As scholars in Sweden prefer to adopt copy-editing services in preparation of publishing papers, resulting in a native-like version of their manuscript which may influence the validity of our comparison, a request letter was sent to the first authors of the previously selected papers to gather additional background information on their article. Based on the reply letters, only research papers that were not polished by any copy-editing services were included in Swedish Corpus.

With the help of WordSmith Tools, the two corpora were searched for the structure "noun + complement" and "noun + be + complement", each including five specific structures following a shell noun: that clause, to-infinitive clause, of-prepositional clause, wh-clause and preposition plus wh-clause. This step was followed by a manual verification of the concordance lines. After identifying the different shell nouns, their frequency and lexico-grammatical patterns were listed, and categorized according to Jiang's taxonomy [8]. A special attention was also paid to the premodifiers used before each shell noun, computing their frequencies and categorizing them based on Schmid's classification [5]. Due to the different size of the two corpora, the frequencies of shell nouns were normalized to 100,000 words for a more reliable comparison. A significance test was applied through Log-likelihood Ratio Calculator [21] to ascertain significant differences in the use of shell nouns by Chinese and Swedish scholars. A difference was accepted to be significant if $\mathrm{p}<0.01$.

\section{Results and discussion}

\subsection{Frequency of Shell Nouns}

The results demonstrate that, overall, the analyzed structures of shell nouns appear 164 times in Chinese Corpus, (120.7 per 100,000 words) and 214 times in Swedish Corpus, (164.23 per 100,000 words). This result is in accordance with that of [16], in which Jiang obtains a frequency of 101 cases per 100,000 words for the "noun + complement" structure of shell nouns in papers of hard science and 328 cases per 100,000 words in soft science. As the present analysis includes both "noun + complement" structure and "noun + be + complement" structure, the frequency is slightly higher than Jiang's but still within an acceptable range. The normalized frequencies indicate that Chinese authors do not use shell nouns as frequently as Swedish authors do. The test of Log-likelihood Ratio confirms this significant difference: $\mathrm{LL}=8.81, \mathrm{p}<.01$.

A comparison is also made between the lexical ranges of shell noun types by calculating how many types of shell nouns occur at different cut-off points. For instance, the shell noun ability is identified 17 times in Chinese Corpus, thus belonging to the "16-20" group. The purpose of doing this categorization is to see whether scholars from the two countries are more likely to use a large variety of shell nouns or employ the same shell noun repeatedly. As presented in Table 4, the distributions of shell noun types in the two corpora are quite similar. Both Chinese and Swedish authors tend to use a large number of shell nouns once, especially Swedish scholars. Shell nouns that are identified twice in the corpus rank second in the list for 
both corpora. Both Chinese and Swedish scholars use only one shell noun 16 to 20 times and only one shell noun is identified in Swedish Corpus for more than 20 times. This means that both groups rather employ a large variety of shell nouns, although some are used only once.

Table 4. Range of shell noun types in the two corpora

\begin{tabular}{|lll|}
\hline Range of shell noun types & Chinese Corpus & Swedish Corpus \\
\hline over 20 & 0 & 1 \\
$16-20$ & 1 & 1 \\
$11-15$ & 3 & 2 \\
$6-10$ & 5 & 8 \\
$4-5$ & 4 & 4 \\
3 & 5 & 4 \\
2 & 11 & 11 \\
1 & 22 & 39 \\
total & 51 & 70 \\
\hline
\end{tabular}

With the purpose of figuring out the reason leading to the difference in overall frequency, the method of Flowerdew [22] is learnt. There are 26 types of shell nouns found in both corpora, and the frequency of those "shared shell nouns" takes a large percentage of the total frequency (74\% in Chinese Corpus and 69\% in Swedish Corpus). Among 25 shell nouns that occur only in Chinese Corpus, 13 of them appear one time. The percentage is even higher for Swedish Corpus: among 44 shell nouns that are only used in it, 34 are employed by the authors only once. The low frequency of such a large number of words, to some degree, might be a result of the small corpus size and the random selection of research papers. If two larger corpora were employed, or some of the research papers were changed, the difference might not be observed.

The most frequently used shell nouns in the two corpora are also identified. The top 10 shell nouns in Chinese Corpus are ability, fact, reason, potential, possibility, assumption, way, aim, capability and need. The top 10 shell nouns in Swedish Corpus are possibility, ability, aim, assumption, fact, goal, hypothesis, importance, purpose and way. Six words overlap among the top 10 shell nouns, indicating that when using shell nouns, Chinese authors and Swedish authors seem to prefer similar words.

\subsection{Classes of Shell Nouns}

When classifying shell nouns according to the function-based classification, both similarities and differences arise. Table 5 and 6 show the classification of shell nouns used in Chinese Corpus and Swedish Corpus, respectively, along with the frequency for each class and sub-class and their percentages.

The entity class is the only class for which Chinese and Swedish authors differ significantly (LL $=10.96, \mathrm{p}<.01)$. However, with the exception of cognition nouns, Chinese scholars make similar use of object nouns, event nouns and discourse nouns as their Swedish counterparts. In Chinese
Corpus, 67 cases of shell nouns fall on the entity class, including 14 cases of object nouns, 19 cases of event nouns, 4 cases of discourse nouns, and 30 cases of cognition nouns. In Swedish Corpus, 107 cases belong to the entity class, which accounts for $50 \%$ of the total number. The number of cases for each sub-category in this corpus is $10,32,12$ and 53 , respectively.

Table 5. The classification of shell nouns in Chinese Corpus

\begin{tabular}{|c|c|c|c|}
\hline Classes & Shell nouns used in the corpus & Frequency & Percentage \\
\hline \multicolumn{2}{|l|}{ Entity } & 67 & $40.8 \%$ \\
\hline object & $\begin{array}{l}\text { case, characteristic, example, } \\
\text { finding, issue, phenomenon, } \\
\text { principle, task }\end{array}$ & 14 & $8.5 \%$ \\
\hline event & $\begin{array}{l}\text { challenge, fact, proof, process, } \\
\text { signal }\end{array}$ & 19 & $11.6 \%$ \\
\hline discourse & conclusion, question & 4 & $2.4 \%$ \\
\hline cognition & $\begin{array}{l}\text { aim, assumption, determination, } \\
\text { disagreement, focus, goal, } \\
\text { hypothesis, key, objective, } \\
\text { strategy, willingness }\end{array}$ & 30 & $18.3 \%$ \\
\hline \multicolumn{2}{|l|}{ Attribute } & 76 & $46.4 \%$ \\
\hline quality & $\begin{array}{l}\text { difficulty, importance, merit, } \\
\text { problem, significance }\end{array}$ & 6 & $3.6 \%$ \\
\hline manner & $\begin{array}{l}\text { condition, constraint, extension, } \\
\text { method, way }\end{array}$ & 14 & $8.6 \%$ \\
\hline status & $\begin{array}{l}\text { ability, capability, capacity, need, } \\
\text { possibility, potential, probability, } \\
\text { tendency, uncertainty }\end{array}$ & 56 & $34.2 \%$ \\
\hline \multicolumn{2}{|l|}{ Relation } & 21 & $12.8 \%$ \\
\hline Relationship & $\begin{array}{l}\text { basis, clue, difference, purpose, } \\
\text { reason, result }\end{array}$ & 21 & $12.8 \%$ \\
\hline \multicolumn{2}{|l|}{ Total } & 164 & $100 \%$ \\
\hline
\end{tabular}

Table 6. The classification of shell nouns in Swedish Corpus

\begin{tabular}{|c|c|c|c|}
\hline Classes & Shell nouns used in the corpus & Frequency & Percentage \\
\hline \multicolumn{2}{|l|}{ Entity } & 107 & $50.0 \%$ \\
\hline object & $\begin{array}{l}\text { aspect, factor, finding, } \\
\text { information, issue, notion, } \\
\text { pattern, theory }\end{array}$ & 10 & $4.7 \%$ \\
\hline event & $\begin{array}{l}\text { activity, attempt, challenge, } \\
\text { drawback, evidence, fact, force, } \\
\text { impact, indication, investigation, } \\
\text { mechanism, process, support }\end{array}$ & 32 & $15.0 \%$ \\
\hline discourse & $\begin{array}{l}\text { explanation, proposition, } \\
\text { question, requirement, suggestion }\end{array}$ & 12 & $5.6 \%$ \\
\hline cognition & $\begin{array}{l}\text { aim, ambition, assumption, doubt, } \\
\text { goal, hypothesis, idea, intention, } \\
\text { motivation, note, objective, point, } \\
\text { prediction, strategy, } \\
\text { understanding, view }\end{array}$ & 53 & $24.7 \%$ \\
\hline \multicolumn{2}{|l|}{ Attribute } & 91 & $42.5 \%$ \\
\hline quality & $\begin{array}{l}\text { advantage, disadvantage, } \\
\text { importance, risk, strength }\end{array}$ & 16 & $7.5 \%$ \\
\hline manner & $\begin{array}{l}\text { approach, condition, limitation, } \\
\text { method, period, time, way }\end{array}$ & 17 & $7.9 \%$ \\
\hline status & $\begin{array}{l}\text { ability, capability, capacity, } \\
\text { chance, inability, necessity, need, } \\
\text { possibility, potential, probability, } \\
\text { trend }\end{array}$ & 58 & $27.1 \%$ \\
\hline \multicolumn{2}{|l|}{ Relation } & 16 & $7.5 \%$ \\
\hline Relationship & $\begin{array}{l}\text { exception, ingredient, purpose, } \\
\text { result, reason }\end{array}$ & 16 & $7.5 \%$ \\
\hline \multicolumn{2}{|l|}{ Total } & 214 & $100 \%$ \\
\hline
\end{tabular}


The entity class in Swedish Corpus is the largest one compared with the other two, which implies that scholars from Sweden are more likely to describe the target itself when expressing their stance. The frequency of cognition nouns used by Swedish scholars is 40.8 cases per 100,000 words, almost two times more than Chinese authors'. However, both groups of authors use cognition nouns mostly in the entity class. Examples (1) to (3) describe the use of cognition nouns.

(1) Therefore, the aim of this study was to explore relationships between SOM characteristics and its releasing effects on phenanthrene (PHE, as a representative of PAHs) sorption kinetics and capacity and discuss the mechanisms involved, by comparing results on rhizosphere sediment collected from lotus pond and higher humified sediment in a previous report. (Chinese Corpus, No.9)

(2) Another idea that Åslund et al. (2008) introduced is to design a forming wire that only allows unidirectional flow and by that hinders rewetting from water that has already penetrated the sheet. (Swedish Corpus, No.22)

(3) It should be emphasized, though, that the sole motivation for choosing this specific thermodynamic model is that it gives good agreement with available data. (Swedish Corpus, No.19)

In Chinese Corpus, 76 cases of shell nouns are found in the attribute class, accounting for $46.4 \%$ of the total occurrences. There are 6 cases of quality nouns, 14 cases of manner nouns, and 56 cases of status nouns. In Swedish Corpus, 91 cases belong to the entity class, which represents $42.5 \%$ of the total number. The frequency of cases for each sub-class is 16,17 and 58 , respectively. The attribute class in Chinese Corpus is the largest among the three classes, indicating that Chinese scholars prefer "to express their attitudinal evaluation and value-laden judgment of entity's attributes" [8], as illustrated in examples (4) and (5) below.

(4) Mild ice can reduce the airplane's flight performance, leading to the decrease of the airplane lift and the increase of resistance, which will cause the difficulty of controlling the flight attitude. (Chinese Corpus, No.1)

(5) Another problem encountered when solenoid valves are used is that there exists residual magnetism that lingers in the valve body after the power has been cut off, causing a delay in the closure of the valves. (Chinese Corpus, No.23)

In both Chinese Corpus and Swedish Corpus, the status noun represents the highest percentage in the attribute class. 7 shell nouns overlap in this group: ability, capability, capacity, need, possibility, potential and probability, taking a comparatively large percentage of the number of shell noun types in this group. Examples (6) and (7) below illustrate how some of these shell nouns are used.

(6) There was a possibility that the performance of the two-stage ejector was influenced by the axial position. (Chinese Corpus, No.21)

(7) The improved ability to determine the position of a prey by using multiple senses may allow for a longer strike distance, which should render a relative benefit to pike under extremely deteriorated visibility conditions where visibility is shorter than prey escape distances. (Swedish Corpus, No.12)

21 cases of relation nouns are used in Chinese Corpus, accounting for $12.8 \%$ of the total occurrence. In Swedish Corpus, 16 cases belong to the relation class $(7.5 \%$ of the total number). The relation class is the smallest one compared with the other two in both corpora, indicating Chinese and Swedish scholars are less likely to describe the relationship a target has with other items. Examples (8) to (11) presents the use of relation nouns. It is worthwhile mentioning that the frequency of relation nouns in Chinese Corpus is 15.5 cases per 100,000 words, which is higher than in Swedish Corpus (12.3 cases per 100,000 words). 3 shell nouns overlap in this class: purpose, reason, and result.

(8) Another difference was that the detonation waves initiated were transited from the deflagration waves propagating to the open end, the same as most of the traditional PDRE. (Chinese Corpus, No.22)

(9) The purpose with this paper is to investigate the relationship between packaging and the influence it has on marketing from a management point of view. (Swedish Corpus, No.6)

(10) Another reason may be the processing of the software that calculated the final results. (Chinese Corpus, No.29)

(11) This conclusion was remarkably well supported by the result that the removal ratio of NB was still $86.0 \%$ at $\mathrm{pH}$ 5.0. (Chinese Corpus, No.17)

\subsection{Patterns of Shell Nouns}

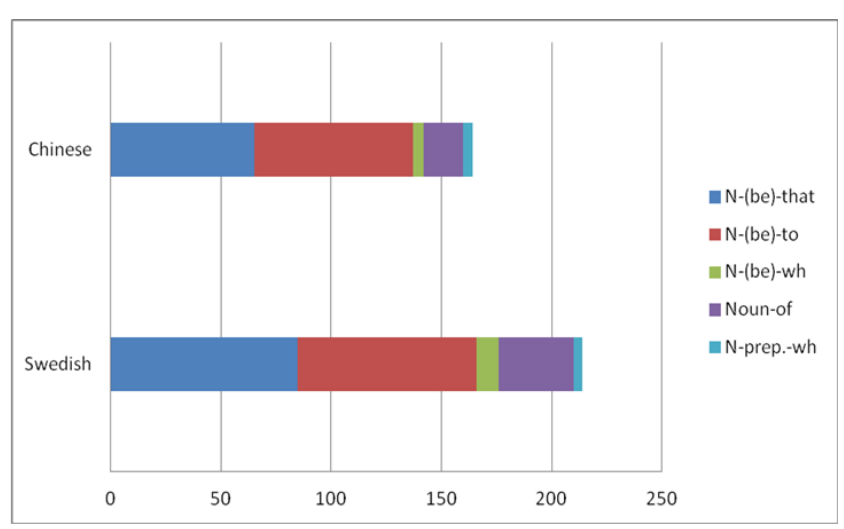

Figure 1. Patterns of shell nouns in the two corpora 
In the "noun + complement" structure and "noun + be + complement" structure, a shell noun is followed by either that-clause, to-infinitive clause, of-prepositional clause, wh-clause or preposition plus wh-clause. As illustrated in Figure 1, the two groups of scholars make similar use of the five patterns mentioned above.

While that clause and to-infinitive clause are the most frequently used patterns by both Chinese and Swedish scholars, preposition plus wh-clause is the least used. No significant difference is found in the selection of these five patterns. Examples (12)-(17) are presented below to illustrate the use of these patterns.

(12) This is due to the fact that the point were using the maximum allowed flow becomes disadvantageous appears earlier for larger particles. (Swedish Corpus, No.26)

(13) A fundamentally different approach is to capture contaminants in the gas stream in non-regenerative filtering and adsorption arrangements. (Swedish Corpus, No.18)

(14) First, if the goal is to minimize the total electricity cost and the maximum tardiness simultaneously, the problem of minimizing the total electricity cost for given maximum tardiness can be solved by using the modified insertion heuristic. (Chinese Corpus, No.12)

(15) One of the challenges is how to make use of the tremendous energy completely from the detonation wave. (Chinese Corpus, No.21)

(16) Therefore, we cannot make a conclusion whether a structural difference between the structures for proteins obtained from native and recombinant sources exists. (Chinese Corpus, No.29)

(17) But the crucial point for this specific business was how the packs would stand the very demanding voyage before ending up on the retailers' shelves" says purchasing manager at the UK Confectionary. (Swedish Corpus, No.7)

\subsection{Premodifiers of Shell Nouns}

The premodifier of shell nouns, as introduced before, is another aspect for analyzing how authors of scientific research papers convey their stance. The times of premodifiers identified in the two corpora are shown in Table 7. The Log-likelihood Ratio Test establishes no significant difference between Chinese and Swedish scholars.

Table 7. Premodifiers of shell nouns identified in the two corpora

\begin{tabular}{|c|c|c|}
\hline Groups & Times in Chinese Corpus & Times in Swedish Corpus \\
\hline Descriptive & 17 & 19 \\
\hline Evaluative & 17 & 12 \\
\hline Classifying & 3 & 2 \\
\hline Restrictive & 11 & 12 \\
\hline Cohesive & 9 & 14 \\
\hline Total & 57 & 59 \\
\hline
\end{tabular}

In Chinese Corpus, descriptive and evaluative premodifiers are most frequently used, both occurring 17 times. Similarly, Swedish scholars also employ descriptive premodifiers most often, 19 occurrences. Premodifiers in the descriptive group express qualities of objects. Words used in this group include biggest, higher, reduced, low, new possible, etc. Examples of descriptive premodifiers are as follows.

(18) The ability to use both YOY and older fish, such as in the Larje River, may increase the reproduction potential of mussel populations, compared to a reduced ability to use more than one year class, such as in the Brattefors River. (Swedish Corpus, No.16)

(19) And then, Chen et al. (2010) tried to test 4A zeolite as the support for nZVI whether it had higher capacity to control iron loss during Fenton-like reaction process. (Chinese Corpus, No.16)

Evaluative premodifiers express the speakers' attitude towards objects. Such adjectives used in the corpora correspond best, crucial, effective, greater, important, significant, etc. Examples (20) and (21) present the use of evaluative premodifiers.

(20) Packaging and packaging design have therefore come increasingly to be seen by firms as an effective way of differentiating product offerings from those of competitors. (Swedish Corpus, No.6)

(21) An important aspect is to understand how customers are using the product and what type of value a new packaging solution can bring to customers. (Swedish Corpus, No.7)

The adjectives of the third group, classifying premodifiers, are used to identify the class to which something belongs. Biochemical and physical are two representative adjectives in this group, as in the following examples:

(22) The changes of NO and PGE2 in turn could be as biochemical signals to influence the function of downstream effector cells, like osteoblasts and osteoclasts. (Chinese Corpus, No.2)

(23) The logistic function includes the way a product travels from a producer to the consumer and the physical requirements that packaging must fulfill within the actual supply chain. (Swedish Corpus, No.6)

The frequency of this group of premodifiers in both corpora remains the lowest among the five groups. A possible reason for that finding is that the selected papers in both corpora are specialized in a certain area, such as biology and physics, and these papers actually have fixed target readers in that area, hence the unnecessary clarification of which class a shell noun belongs to.

According to Schmid [5], restrictive premodifiers are borrowed from Quirk et al. [23], who state that "restrictive 
adjectives restrict the reference of the noun exclusively, particularly, or chiefly". Words in this group include main, major, our, overall, sole, their, etc. The two examples of restrictive premodifiers found in the corpora are illustrated below.

(24) To help the farmers to improve their adaptive capacity to promote sustainable agricultural development, governments should: Develop additional adaptation measures. (Chinese Corpus, No.24)

(25) The main aim of the change of material was to eliminate the slight flavour, but also to improve the environmental issues. (Swedish Corpus, No.6)

The last group is cohesive premodifiers, which includes words such as another, first, second and similar. This notion is based on Halliday and Hasan's work [2], in which such adjectives are means of creating cohesion in research papers. The use of these adjectives is shown below.

(26) Another example is that nitration of tyrosine 10 critically enhanced amyloid $\beta$ (A $\beta$ ) aggregation and plaque formation which contributed to Alzheimer's disease (AD) pathology. (Chinese Corpus, No.26)

(27) A second aim was to compare the time- and cost-efficiency of the two methods. (Swedish Corpus, No.17)

\section{Further Discussion}

This comparison presents that though Chinese scholars use significantly less shell nouns especially in the cognition class compared with Swedish scholars, the two groups of scholars have no significant difference in choosing lexico-grammatical patterns, premodifiers or other classes of shell nouns. That is to say, with fewer differences, Chinese scholars and Swedish scholars tend to have more similarities when using shell nouns in academic papers.

The difference in the overall frequency could be a result of the small corpus size and random selection of the research papers. According to our analysis, the most important factor that leads to the significant difference in overall frequency may be attributed to a large number of shell nouns that are only used once in the two corpora. As Chinese and Swedish scholars do not have a reliance on these shell nouns, they may not be found if some papers in the two corpora were changed.

According to Swales' definition of discourse community [24], "there are common goals, participatory mechanisms, information exchange, community specific genres, a high specialized terminology, and a high general level of expertise" in discourse communities. Members in a specific discourse community provide a rationale that determines the constraining conventions of the genre's schematic structure and lexical and syntactic choice. Research article is the specific genre in this study and both
Chinese and Swedish scholars "live in" the same discourse community. Restricted by rules and regulations in this genre, they have to follow the lexical and syntactic conventions of research papers, which make their use of shell nouns in academic writing similar with each other.

\section{Conclusions}

The results in this paper indicate that even though Chinese and Swedish scholars have different first languages and cultural backgrounds, they adopt shell nouns in a quite similar way in academic writing. This finding to some degree illustrates that conventions of a genre play a more important role than first language transfer and cultural aspects in academic writing. Therefore, language teachers, especially those who teach non-native speakers of English, should be aware of this principle and ask students to pay special attention to a genre's schematic structure, as well as their lexical and syntactic choices.

Language teachers can also use the examples selected from authentic research papers to teach students who do not know how to employ shell nouns in a proper way. In academic writing courses, explicit instruction is necessary to demonstrate that shell nouns in different classes are used to mark entities, describe attributes or discuss the relations and what specific items can be selected in each class. Various tasks to improve the students' awareness of using different lexico-grammatical patterns of shell nous can be of great use as well.

\section{Acknowledgements}

This research is supported by the Seed Foundation of Innovation and Creation for Graduate Students in Northwestern Polytechnical University (No. Z2017062).

\section{REFERENCES}

[1] Aktas, R. N., \& Cortes, V. (2008). Shell nouns as cohesive devices in published and ESL student writing. Journal of English for Academic Purposes, 7(1), 3-14.

[2] Halliday, M. A. K., \& Hasan, R. (1976). Cohesion in English. London: Longman.

[3] Francis, G. (1986). Anaphoric nouns. Birmingham: University of Birmingham.

[4] Ivanic, R. (1991). Nouns in search of a context: a study of nouns with both open-and closed-system characteristics. IRAL, 29(2), 93-114.

[5] Schmid, H. (2000). English abstract nouns as conceptual shells: From corpus to cognition. Berlin: Walter de Gruyter.

[6] Liu, Q. \& Wang, X. Y. (2016). Research on shell nouns in 
abstracts of master theses by science and engineering majors, Foreign Language World, 2, 52-60.

[7] Hunston, S., \& Francis, G. (2000). Pattern grammar. Amsterdam: Benjamins.

[8] Jiang, F. (2015). Nominal stance construction in 11 and 12 students' writing. Journal of English for Academic Purposes, 20, 90-102.

[9] Niu, Q.Q. (2012). A Comparative Study on the Use of Shell Nouns in Academic Writings by EFL Learners and Published Writers. (Master thesis), Nanjing University.

[10] Flowerdew, J. (2006). Use of signalling nouns in a learner corpus. International Journal of Corpus Linguistics, 11(3), 345-362.

[11] Zhang, H. \& Zhang, Y. H. (2007). A comparative study of the presentation of clausal information of shell nouns in English learners' dictionaries. Foreign Language Research, $1,59-65$.

[12] Jiang, F. (2016). Stance construction and interpersonal interaction of shell nouns. Modern Foreign Languages, 4, $470-482$.

[13] Zhou, H. \& Liu, Y. B. (2015). Investigating the function and the stance of signaling nouns in Chinese EFL learners' English academic writing. Foreign Language Teaching and Research, 2, 251-261+321.

[14] Lian, S. N. (2010). Contrastive Studies of English and Chinese. Beijing: Higher Education Press.

[15] Selinker, L. (1972). Interlanguage. International Review of
Applied Linguistics in Language Teaching, 10(3), 209-232.

[16] Jiang, F. (2015). Entity, attribute and relation: The trichotomy of shell nouns and their interpersonal functions. Corpus Linguistics, 2(2), 62-74.

[17] Jiang, F. (2015). Stance nouns in argumentative essays by Chinese and American university students - A corpus based comparative study. Foreign Languages and Their Teaching, $5,8-14$.

[18] Francis, G. (1994). Labelling discourse: an aspect of nominal-group lexical cohesion. In M. Coulthard (Ed.), Advances in Written Text Analysis (pp. 83-101). London: Routledge.

[19] Flowerdew, J., \& Forest, R. W. (2015). Signalling nouns in English: A corpus-based discourse approach. Cambridge: Cambridge University Press.

[20] Xu, Y. L. (2002). Contrastive Linguistics. Shanghai: Shanghai Foreign Language Education Press.

[21] Liang, M. C. et al., (2010). Using Corpora: A Practical Coursebook. Beijing: Foreign Language Teaching and Research Press.

[22] Flowerdew, J. (2003). Signalling nouns in discourse. English for Specific Purposes, 22, 329-346.

[23] Quirk et al. (1985). A Comprehensive Grammar of the English Language. London: Longman.

[24] Swales, J. M. (1990). Genre Analysis: English in Academic and Research Settings. Cambridge: Cambridge University Press. 